Revista Brasileira de Agricultura Irrigada v.8, no. 6, p.488 - 501, 2014

ISSN 1982-7679 (On-line)

Fortaleza, CE, INOVAGRI - http://www.inovagri.org.br

DOI: $10.7127 /$ rbai.v8n600262

Protocolo 262.14 - 22/08/2014 Aprovado em 21/10/2014

\title{
MAPEAMENTO DO USO DA ÁGUA E DO SOLO APLICADO NA DETERMINAÇÃ̃ DA ÁREA MÁXIMA PARA PLANTIO DE CENOURA E TRIGO IRRIGADOS NO RIO ABAETÉ (MG)
}

Reynaldo Furtado Faria Filho ${ }^{1}$, Samuel Petraccone Caixeta ${ }^{2}$, Washington Luiz Assunção ${ }^{3}$

\section{RESUMO}

O mapeamento da água e do solo se torna cada vez mais importante à medida que a população mundial aumenta. Entretanto, estes mapeamentos requerem a integração de muitas informações sendo necessária a utilização dos sistemas de informação geográfica (SIG) para facilitar e possibilitar o desenvolvimento dos mesmos. Portanto, objetivou-se realizar o mapeamento e a quantificação do uso da água e do solo na cabeceira do rio Abaeté com auxílio do SIG. Determinou-se a área máxima possível para plantio de cenoura e trigo, no período de abril a julho de 2012, em função da vazão máxima possível de ser outorgada. O mapa de uso do solo foi gerado a partir da imagem do Google de 14/09/2005. A demanda de água de cada cultura foi determinada pela evapotranspiração da cultura (ETc) e a oferta de água por meio da precipitação. Foram identificados os seguintes usos atuais do solo: café, terra preparada, soja, mata, eucalipto, cenoura, milho, milheto, pastagem, construção, rodovia e área de preservação permanente (APP). Foram encontrados 7 poços no qual são retirados, aproximadamente, $2.263 \mathrm{~L} \mathrm{~h}^{-1}$ de água e 10 captações em rios e nascentes totalizando $357.570 \mathrm{~L} \mathrm{~h}^{-1}$. Os usos da água identificados foram a irrigação, dessedentação animal, abastecimento humano, lavadores de cenoura e máquinas agrícolas. Verificou-se que para o período de abril a julho, é possível cultivar 322,69 ha de cenoura irrigada e ou 351,56 ha de trigo irrigado, o que representa $18 \%$ e 20 $\%$, respectivamente, da área total possível de ser cultivada na área estudada.

Palavras-chave: imagens Google, outorga, SIG.

\section{MAPPING OF WATER AND SOIL USE APPLIED TO DETERMINE THE MAXIMUM ÁREA FOR PLANTING IRRIGATED WHEAT AND CARROT IN RIO ABAETÉ (MG)}

\footnotetext{
ABSTRACT

${ }^{1}$ Engenheiro Agrimensor, Prof ${ }^{\mathrm{o}}$ Assistente, Universidade Federal de Viçosa - Campus de Rio Paranaíba, UFV, Rio Paranaíba - MG. Email: reynaldo.filho@ufv.br

${ }^{2}$ Engenheiro Agrônomo, Prof ${ }^{\circ}$ Temporário, Universidade Federal de Viçosa - Campus de Rio Paranaíba, UFV, Rio Paranaíba - MG. Email: samuelpetraccone@ hotmail.com

${ }^{3}$ Geógrafo, Prof ${ }^{\mathrm{o}}$ Adjunto II, Universidade Federal de Uberlândia, UFU, Uberlândia - MG. Email:

wlassuncao@gmail.com
} 
Water and soil mapping has become increasingly important as world population grows. However, these mappings demand the integration of lots of information. The use of geographic information systems (GIS) is necessary to allow and facilitate the development of mappings. Therefore, the present work aimed to perform the mapping and quantification of water and soil use in the headwaters of the Abaeté River with the aid of GIS. It was determined the maximum possible area for planting carrot and wheat,from April to July 2012, according to the maximum possible flow to be granted. The map of land use was generated from the Google image of September 14, 2005. The water demand of each culture was determined by crop evapotranspiration (ETc) and water supply, by precipitation. The following soil uses were identified: coffee, prepared soil, soybean, woods, eucalyptus, carrots, corn, millet, pasture, construction, highways and permanent preservation areas (APP). Seven wells were found, which provide approximately $2.263 \mathrm{~L}$ $\mathrm{h}^{-1}$ of water. Water is also collected from ten sites in rivers and streams, totaling $357.570 \mathrm{~L}$ $\mathrm{h}^{-1}$. The following water uses were identified: irrigation, animal watering, human consumption, washing of carrot and farm machinery. It was found that from April to July, it is possible to cultivate 322.69 hectares of irrigated carrot and/or 351.56 ha of irrigated wheat, which account for $18 \%$ and $20 \%$, respectively, of the total cultivable land in the area under study.

Keywords: Google images, grants, SIG.

\section{INTRODUÇÃO}

$\mathrm{O}$ homem retira da natureza materiais de consumo, como alimentos, minérios, combustível fóssil, madeira e seus derivados para suprir suas necessidades e anseios (TESTONI, 2010). Esta retirada gera consequências nocivas à manutenção do equilíbrio ambiental. Assim, de acordo com (GLUFKE, 1999), torna-se necessário adotar medidas para recuperação das áreas degradadas que foram exploradas inadequadamente, bem como, fazer o uso racional e o manejo sustentado dos recursos naturais renováveis.

Para que se torne possível o desenvolvimento sustentável é fundamental a utilização da bacia hidrográfica como instrumento norteador das ações do poder público e da sociedade, em longo prazo, no controle do uso dos recursos ambientais pelo homem (LANNA, 2000).

Devido ao crescimento populacional, a urbanização e à intensificação das atividades agrícolas e industriais que ocorreram a partir da década de 70 no Brasil busca-se um modelo de exploração racional que não acarrete ou que minimize os danos aos recursos naturais (FERREIRA JÚNIOR et al., 2009), o qual garante o bem-estar a presente população e consequentemente para as gerações futuras.

Neste contexto, um dos recursos naturais mais impactados pela ação do homem são os recursos hídricos (FERREIRA JÚNIOR et al., 2009). A água se configura como principal insumo a ser analisado quando se pensa em desenvolvimento sustentável. Devido ao uso múltiplo da água ocorrem com frequência os conflitos de uso o que têm motivado a adoção de medidas que objetivam disciplinar o uso da água (OLIVEIRA et al., 2007). Além dos conflitos as atividades humanas podem alterar a qualidade das águas comprometendo a vida aquática e restringindo os possíveis usos do recurso hídrico (MERTEN \& MINELLA, 2002).

De acordo com Tonello (2005) as atividades desenvolvidas no solo de uma bacia hidro- 


\section{MAPEAMENTO DO USO DA ÁGUA E DO SOLO APLICADO NA DETERMINAÇÃO DA ÁREA MÁXIMA PARA PLANTIO DE CENOURA E TRIGO IRRIGADOS NO RIO ABAETÉ (MG)}

gráfica indicam a situação ambiental, da mesma, bem como as características físico-químicas das águas. Com isso, torna-se necessário levantamentos detalhados do uso do solo para todo o Brasil em escala que permitam solucionar problemas referentes ao uso do solo, prevenção e recuperação de áreas degradadas, manejo e conservação do solo (SANTOS, 2007).

Portanto, para que se faça o gerenciamento de bacias hidrográficas, no que concerne aos usos da água e solo, é necessária a integração e análise de um grande número de informações que é onerosa quando realizada pelos métodos convencionais. Como a maior parte destas informações pode ser representada espacialmente por meio de mapas é frequente a utilização dos sistemas de informação geográfica (SIG) que possuem grande potencial para integração de dados subsidiando o gerenciamento das informações em bacias (ROCHA, 2000; DUARTE et al., 2004).

A partir do mapa de uso do solo e da água juntamente com as informações de disponibilidade de água é possível determinar a área possível de se plantar determinada cultura irrigada nos períodos de seca, permitindo-se o planejamento à nível de bacia hidrográfica reduzindo os impactos ambientais que poderiam ser causados pelo mau uso da água e do solo.

Diante do exposto os objetivos do presente estudo foram: mapear e quantificar o uso atual da água e do solo na cabeceira do rio Abaeté com auxilio de sistemas de informações geográficas (SIG); e determinar a área máxima possível de plantio de cenoura e trigo, no período de abril a julho, na cabeceira do rio Abaeté em função da vazão máxima possível de ser outorgada ( $30 \%$ da $\left.\mathrm{Q}_{7,10}\right)$.

\section{MATERIAL E MÉTODOS}

A Figura 1 apresenta o fluxograma com os procedimentos adotados neste estudo. Neste fluxograma é possível verificar os dados de entrada, as ferramentas utilizadas e os resultados encontrados. Nos tópicos seguintes será detalhado cada um destes elementos.

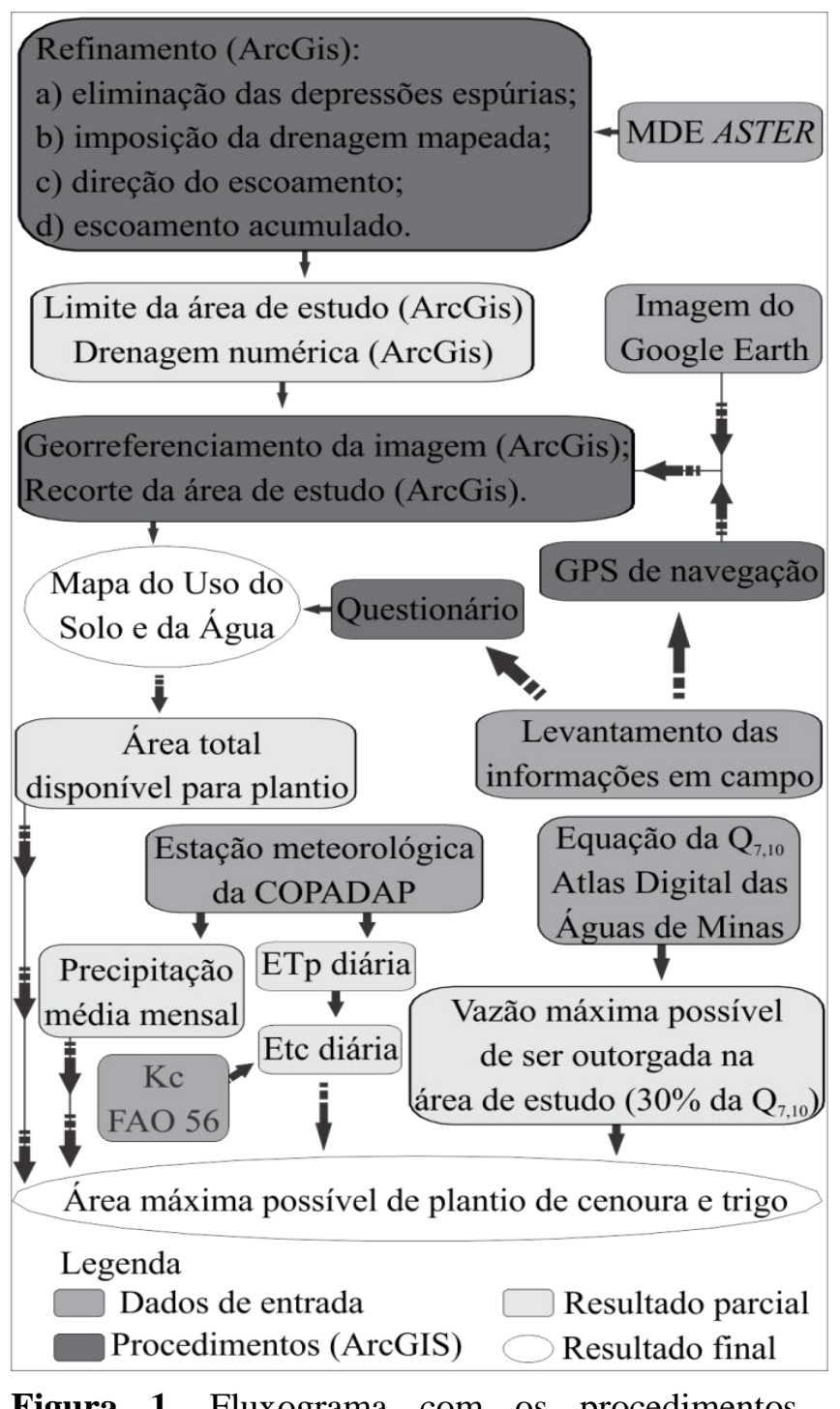

Figura 1. Fluxograma com os procedimentos adotados.

Na realização deste estudo, utilizou-se os módulos ArcCatalog e ArcMap do software ArcGis 9.3, o qual, é um Sistema de Informações Geográficas, desenvolvido pelo Environmental Systems Research Institute - 
ESRI. Os dados de entrada foram trabalhados no sistema de coordenadas UTM e datum SIRGAS 2000, visando a sua uniformidade, no que se refere aos parâmetros cartográficos.

\section{Caracterização da área de estudo}

O estudo foi desenvolvido na cabeceira do rio Abaeté, que está localizado no limite dos municípios de São Gotardo e Rio Paranaíba, localizados no Alto Paranaíba, totalizando uma área de aproximadamente $25,51 \mathrm{~km}^{2}$, conforme é apresentado na Figura 2.

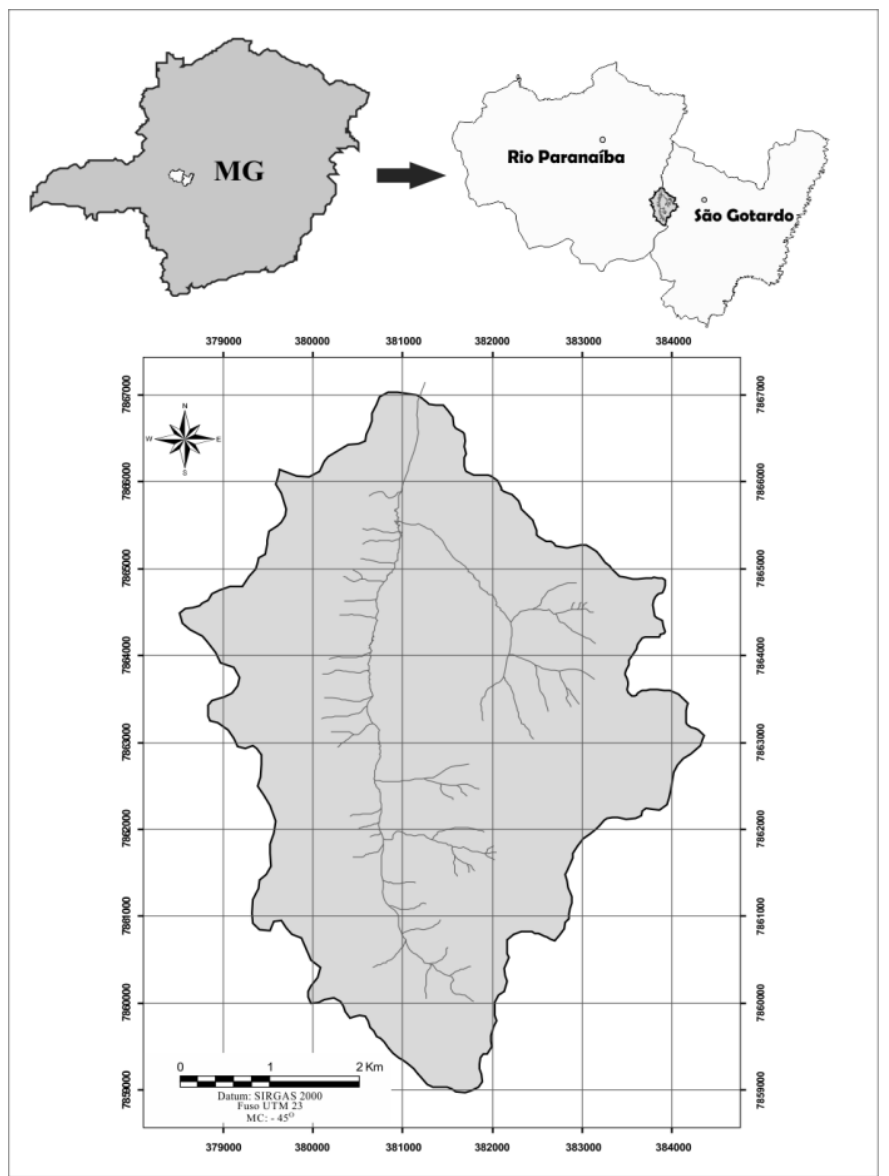

Figura 2. Área de estudo.

O Rio Abaeté é um dos principais afluentes mineiro da margem esquerda do Rio São Francisco, drenando uma área de 5.244 km² (0,8\% da área da Bacia do Rio São Francisco). Percorre uma extensão de $306,61 \mathrm{~km}$ e drena área de nove municípios das mesorregiões do
Triângulo Mineiro e Alto Paranaíba e da Central Mineira.

O clima da região, segundo a classificação de Köppen, é do tipo Cwa, de zona tropical semi-úmida, caracterizado pela presença de duas estações bem definidas, uma fria e seca, abrangendo os meses de abril a setembro, e outra quente e chuvosa, que se estende de outubro a março, como pode ser observado na Figura 3. A precipitação pluvial média anual é de $1.600 \mathrm{~mm}$.

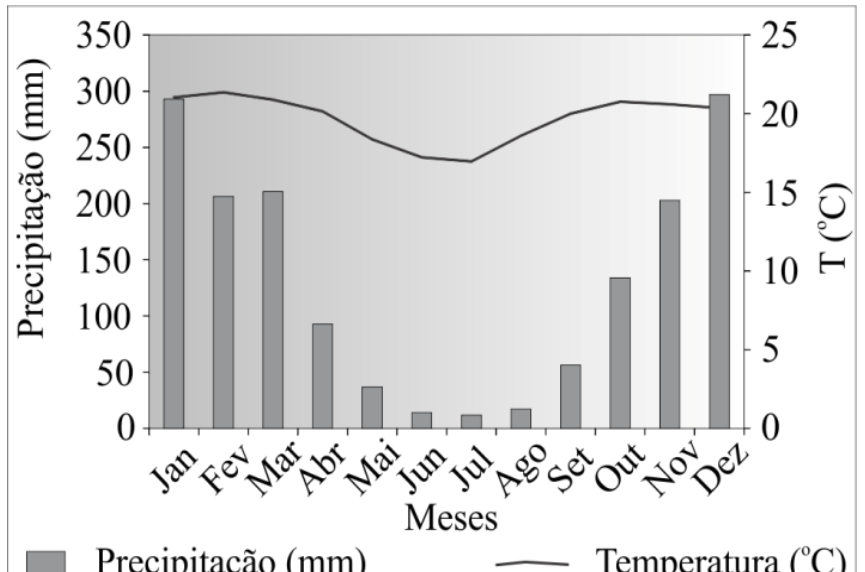

Figura 3. Diagrama ombrotérmico da região de São Gotardo-MG (1981-2009).

A principal atividade econômica é a agricultura, destacando-se as culturas de café, milho, soja, feijão, sorgo, trigo, alho, cenoura, cebola, batata e abacate, além da pecuária leiteira e de corte.

\section{Mapa do uso do solo e da água para a região estudada}

O mapa de uso do solo foi gerado no ArcGis a partir de interpretação visual da imagem disponível no Google Earth (gerada em 14/09/2005 e obtida em 10/04/2012) e de sua validação em campo. Gerou-se manualmente na tela do computador feições que contornaram os limites de cada uso do solo na imagem e fez a sua conferência em campo. A validação do 
mapa de uso em campo é necessária, pois a agricultura é dinâmica modificando a paisagem constantemente e a imagem obtida no Google Earth pode não ter sido gerada para a região recentemente.

O uso da água foi mapeado em forma de pontos de captação de água, tanto de poço quanto de rio, nascentes ou barragens. Para cada ponto de captação foi identificado à utilização da água bem como a quantidade consumida por hora.

Para a delimitação da área de estudo obteve-se o modelo digital de elevação (MDE) com resolução espacial de $30 \mathrm{~m}$, disponibilizado pela NASA (National Aeronautics and Space Administration). Este MDE foi gerado pelo sistema ASTER (Advanced Spaceborne Thermal Emission Reflection Radiometer) o qual é um instrumento do satélite Terra que engloba o Sistema de Observação da Terra (Earth Observing System - EOS) (ENVI, 2011).

Realizou-se o refinamento do MDE ASTER conforme metodologia amplamente empregada e descrita por Ribeiro et al. (2002). Esta metodologia envolve a eliminação das depressões espúrias, imposição da drenagem mapeada, geração de um arquivo com a direção do escoamento e um com o escoamento acumulado. Neste trabalho não serão apresentados os detalhes desta metodologia por esta ser aplicada com reconhecida eficiência e por não ser o foco deste estudo.

De posse do MDE ASTER final utilizouse o módulo Spatial Analist do ArcGis para gerar o limite da sub-bacia estudada, para isso definiu-se as coordenadas $\mathrm{E}=381.188 \mathrm{~m}$ e $\mathrm{N}=$ $7.866 .983 \mathrm{~m}$ como ponto final da bacia. Posteriormente, gerou-se a drenagem numérica correspondente às áreas com escoamento acumulado maiores que 30 células. Esta dre- nagem numérica foi convertida para um arquivo vetorial e passou por uma edição para que se adequasse aos cursos d'água apresentados na imagem. A drenagem numérica gerada no formato matricial foi convertida para o vetorial, visando facilitar sua posterior edição.

Para obtenção da imagem definiu-se uma área retangular que abrangesse toda a região a ser estudada por meio de suas coordenadas UTM e procedendo-se o download da mesma por meio do Google Earth. Posteriormente, a imagem foi georreferenciada por meio do modulo Georeferencing do ArcGis. Para isto, utilizou-se 8 pontos de controle que foram identificados em campo e na imagem. A seguir a imagem georreferenciada foi recortada para a área de estudo.

Atualmente, com a crescente necessidade de informação em diversas áreas, o Google Earth se apresenta como uma boa ferramenta para a obtenção de imagens de alta resolução espacial, visto que estas imagens se forem compradas ainda possuem um preço relativamente alto. A imagem gratuita se for utilizada com técnicas de processamento de imagens corretos podem trazer uma classificação do uso e ocupação do solo mais ou tão preciso quanto às geradas a partir de imagens Landsat, que apesar de gratuitas, têm baixa resolução espacial (TORLAY, 2010).

De posse da imagem georreferenciada do Google Earth impressa, um GPS de navegação da marca Garmin, uma câmera fotográfica e questionários, identificou-se cada área da imagem correspondente em campo e coletou-se informações de uso da água e solo. Para cada propriedade (fazenda) foi realizada uma breve entrevista com o proprietário/funcionário anotando-se as informações em um questionário. As informações coletadas foram: 
área total da propriedade, uso da água (abastecimento humano, irrigação, dessedentação animal, dentre outras), tipo de captação da água (poço, rio, represa), plantas cultivadas, sistema de irrigação (pivô, canhão, aspersão, gotejamento). Os pontos de coleta das informações foram identificados, por meio de suas coordenadas UTM, no GPS e na imagem.

\section{Área máxima possível para plantio de cenoura e ou trigo irrigado}

Neste trabalho buscou-se quantificar a área máxima possível de cultivo de cenoura e trigo no período de abril a julho (época seca) utilizando a vazão máxima possível de ser outorgada para a sub-bacia estudada. Para isto, determinou-se a demanda de água de cada cultura pela evapotranspiração da cultura $\left(\mathrm{ET}_{\mathrm{c}}\right)$ e a oferta de água por meio da precipitação, com base na série histórica do posto da COOPADAP - Cooperativa Agropecuária do Alto Paranaíba para o período de 1981 a 2009, e o volume de água máximo possível de ser outorgado em toda a sub-bacia estudada, de acordo com os critérios adotados pelo IGAM - Instituto Mineiro de Gestão das Águas.

A outorga do direito de uso é o instrumento pelo qual o poder público faz a partição, entre os diversos usuários requerentes, dos recursos hídricos existentes e necessários aos diversos usos a que se destinam. No Estado de Minas Gerais, o IGAM é, atualmente, o responsável pelo planejamento e administração de todas as ações direcionadas à preservação da quantidade e da qualidade das águas, sendo também responsável pela gestão dos recursos hídricos do Estado (IGAM $a, 2012$ ).

Por meio do Decreto $n^{\circ} 40.055$ de 16 de novembro de 1998 são regulamentadas as atribuições do IGAM, cabendo-lhe, entre outras atividades, conceder a outorga do direito de uso das águas, após consulta ao Comitê da respectiva bacia hidrográfica. Devido ao lento processo de implantação dos Comitês de Bacia Hidrográfica, o IGAM tem concedido outorgas de direito de uso dos recursos hídricos baseado na Portaria $n^{\circ}$ 010/98, que estabelece critérios baseados em "vazões de referência" a serem utilizadas para cálculo das disponibilidades hídricas em cada seção de interesse (IGAM $b$, 2012).

O parágrafo $1^{\circ}$ do artigo $8^{\circ}$ da Portaria 010/98 estipula que "até que se estabeleça as diversas vazões de referência na Bacia Hidrográfica, será adotada a $\mathrm{Q}_{7,10}$ (vazão mínima de sete dias de duração e dez anos de recorrência), para cada Bacia"; Resolve no parágrafo $2^{\circ}$ do mesmo artigo "fixar em $30 \%$ (trinta por cento) da $\mathrm{Q}_{7,10}$, o limite máximo de derivação consuntiva a serem outorgadas na porção da bacia hidrográfica limitada por cada seção considerada, em condições naturais, ficando garantida, a jusante de cada derivação, fluxos residuais mínimos equivalentes a $70 \%$ (setenta por cento) da $\mathrm{Q}_{7,10}$.

Visando auxiliar a tomada de decisão de órgãos púbicos bem como os usuários de água o programa de pesquisa e desenvolvimento de tecnologia HIDROTEC disponibilizou, por meio do Atlas Digital das Águas de Minas, as equações para determinação de diversas vazões em Minas Gerais e, dentre elas, a $\mathrm{Q}_{7,10}$. As equações disponibilizadas no Atlas possuem, como única variável independente, a área de drenagem da bacia, facilitando, assim, sua aplicação (EUCLYDES, 2012). Para a sub-bacia 
em estudo, a equação da $\mathrm{Q}_{7,10}$ apresentada no Atlas é

$$
Q_{7,10}=0,0058 A^{0,9211}
$$

em que

$\mathrm{Q}_{7,10}=$ vazão mínima de sete dias de duração e dez anos de recorrência $\left(\mathrm{m}^{3} \mathrm{~s}^{-1}\right)$; e

$\mathrm{A}=$ área de drenagem a montante da seção fluvial $\left(\mathrm{km}^{2}\right)$.

A partir da determinação da $\mathrm{Q}_{7,10}$ calculou-se a $30 \%$ da $\mathrm{Q}_{7,10}$ que é o valor máximo possível de ser outorgado.

Os dados climatológicos utilizados para obtenção da ETp diária foram obtidos a partir da estação meteorológica da COPADAP para o período de observação de 1981 a 2009. A escolha desta estação se deu pela proximidade da mesma com a sub-bacia estudada.

$\mathrm{Na}$ estimativa da evapotranspiração potencial diária utilizou-se o método ajustado por Ribeiro (2000), o qual considera as particularidades desta região. Este método se mostrou adequado para as condições climáticas do cerrado brasileiro, visto que corrige as distorções da evapotranspiração apresentadas no modelo proposto por Camargo (1971) que subestima a evapotranspiração. $\mathrm{O}$ modelo ajustado por Ribeiro (2000) considera a interação de cinco grandezas conforme representado na Equação 2.

$$
\text { ETp diária }=Q_{0} \times T_{m} \times F_{1} \times F_{2} \times F_{3}
$$

em que:

ETp diária = evapotranspiração potencial $(\mathrm{mm})$;
$\mathrm{Q}_{0}=$ radiação solar incidente em superfície horizontal acima da atmosfera, em milímetros de evaporação equivalente, no $15^{\circ}$ dia de cada mês;

$\mathrm{T}_{\mathrm{m}}=$ temperatura média diária $\left({ }^{\circ} \mathrm{C}\right)$;

$\mathrm{F}_{1}=$ fator de ajuste relativo às estações do ano;

$\mathrm{F}_{2}=$ fator de ajuste em relação à umidade relativa média do ar;

$\mathrm{F}_{3}=$ fator de ajuste relativo à velocidade do vento.

$\mathrm{O}$ parâmetro $\mathrm{Q}_{0}$ e os fatores de ajuste $\mathrm{F}_{1}$, $\mathrm{F}_{2}$, e $\mathrm{F}_{3}$ estão apresentados nas Tabelas 1 e 2 . Na Tabela 1 observa-se os valores de $\mathrm{Q}_{0}$ que é a radiação solar incidente em superfície horizontal acima da Atmosfera, em milímetros de evaporação equivalente, no dia 15 de cada mês. Estes valores são referentes ao período (abril a julho) para o intervalo de Latitude da área de estudo (19 $16^{\prime}$ ' a $\left.19^{\circ} 23^{\prime}\right)$.

Tabela 1. $\left(\mathrm{Q}_{\mathrm{o}}\right)$ - Radiação solar incidente em superfície horizontal

\begin{tabular}{ccccc}
\hline Latitude Sul & Abril & Maio & Junho & Julho \\
\hline 18 & 12,7 & 10,9 & 10,0 & 10,4 \\
20 & 12,4 & 10,6 & 9,6 & 10,0 \\
\hline
\end{tabular}

A Tabela 2 apresenta o fator de ajuste $F_{1}$, que é um fator de ajuste relativo às estações do ano para a região do cerrado, o fator de ajuste $F_{2}$ o qual refere-se à umidade relativa média do ar e $\mathrm{o}$ fator de ajuste $\mathrm{F}_{3}$ que considera a capacidade que o vento possui em acelerar o processo evaporativo ao remover, da superfície foliar, o excesso de umidade anteriormente evaporada que é estimado pela Escala Beaufort. 
Tabela 2. Fatores de ajuste $\mathrm{F}_{1}, \mathrm{~F}_{2}$, e $\mathrm{F}_{3}$

\begin{tabular}{cccccc}
\hline & & \multicolumn{5}{c}{$\begin{array}{c}\text { Força } \\
\text { do } \\
\text { Estação do } \\
\text { Ano }\end{array}$} & $\begin{array}{c}\mathrm{F}_{1} \\
10^{-2}\end{array}$ & $\begin{array}{c}\text { Urm } \\
\text { vento } \\
\mathrm{m} \mathrm{s}^{-1}\end{array}$ & $\mathrm{~F}_{3}$ \\
& & & & & \\
& & & & & \\
Primavera & 1,10 & $80-89$ & 0,95 & $0-1$ & 1,00 \\
Verão & 1,20 & $70-79$ & 1,00 & $2-3$ & 1,10 \\
Outono & 1,05 & $60-69$ & 1,05 & $4-5$ & 1,15 \\
Inverno & 1,00 & $50-59$ & 1,10 & 6 & 1,20 \\
& & $40-49$ & 1,15 & $>6$ & 1,00 \\
& & $<40$ & 1,20 & & \\
\hline
\end{tabular}

Para o trabalho proposto utilizou-se o boletim número 56 da Organização das Nações Unidas para Agricultura e Alimentação (FAO) na determinação do coeficiente da cultura $\left(\mathrm{K}_{\mathrm{c}}\right)$ bem como na duração de cada fase fenológica para as culturas da cenoura e trigo (ALLEN et al., 1998). O $\mathrm{K}_{\mathrm{c}}$ é utilizado para determinar a $\mathrm{ET}_{\mathrm{c}}$ diária conforme observa-se na Equação 3.

$$
\mathrm{ETc} \text { diária }=\mathrm{ETp} \times \mathrm{K}_{\mathrm{c}}
$$

em que:

$\mathrm{ET}_{\mathrm{c}}$ diária = evapotranspiração da cultura $(\mathrm{mm})$;

$\mathrm{ET}_{\mathrm{p}}$ diária $=$ evapotranspiração potencial $(\mathrm{mm})$; $\mathrm{K}_{\mathrm{c}}=$ coeficiente da cultura .

Na Figura 4, apresenta-se o gráfico com os valores do coeficiente da cultura e duração de cada fase fenológica a partir da germinação, para a cenoura e o trigo de acordo com boletim da FAO 56 (ALLEN et al., 1998).

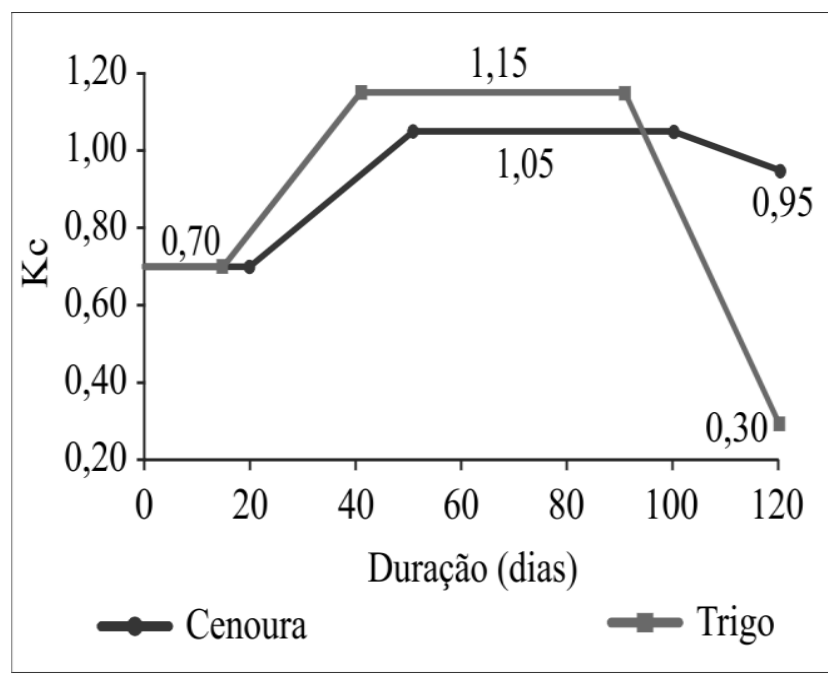

Figura 4. Gráfico com coeficiente das culturas $\left(\mathrm{K}_{\mathrm{c}}\right)$.

\section{RESULTADOS E DISCUSSÃO}

Mapa do uso do solo e da água para a região estudada

A partir do MDE ASTER refinado para a região estudada foi possível inferir que a altitude da região estudada variou de 1.020 a $1.192 \mathrm{~m}$. A Figura 5 apresenta a imagem do Google Earth. Esta imagem foi obtida em 14/09/2005, portanto existe uma defasagem temporal na mesma. Para a classificação da imagem foi necessário ir a campo para verificar as alterações espaciais que ocorreram desde a obtenção da imagem até a data de desenvolvimento do estudo.

Foram identificados os seguintes usos atuais: café, terra preparada, soja, mata, eucalipto, cenoura, milho, milheto, pastagem, construção, rodovia e área de preservação permanente (APP). Vale ressaltar, que o uso denominado construção são as áreas em que não existe a possibilidade de plantio de nenhuma cultura visto que estão ocupadas com construções de galpões, casas, fábricas, dentre outros. Enquanto que rodovia engloba a BR 354 e MG 235. 


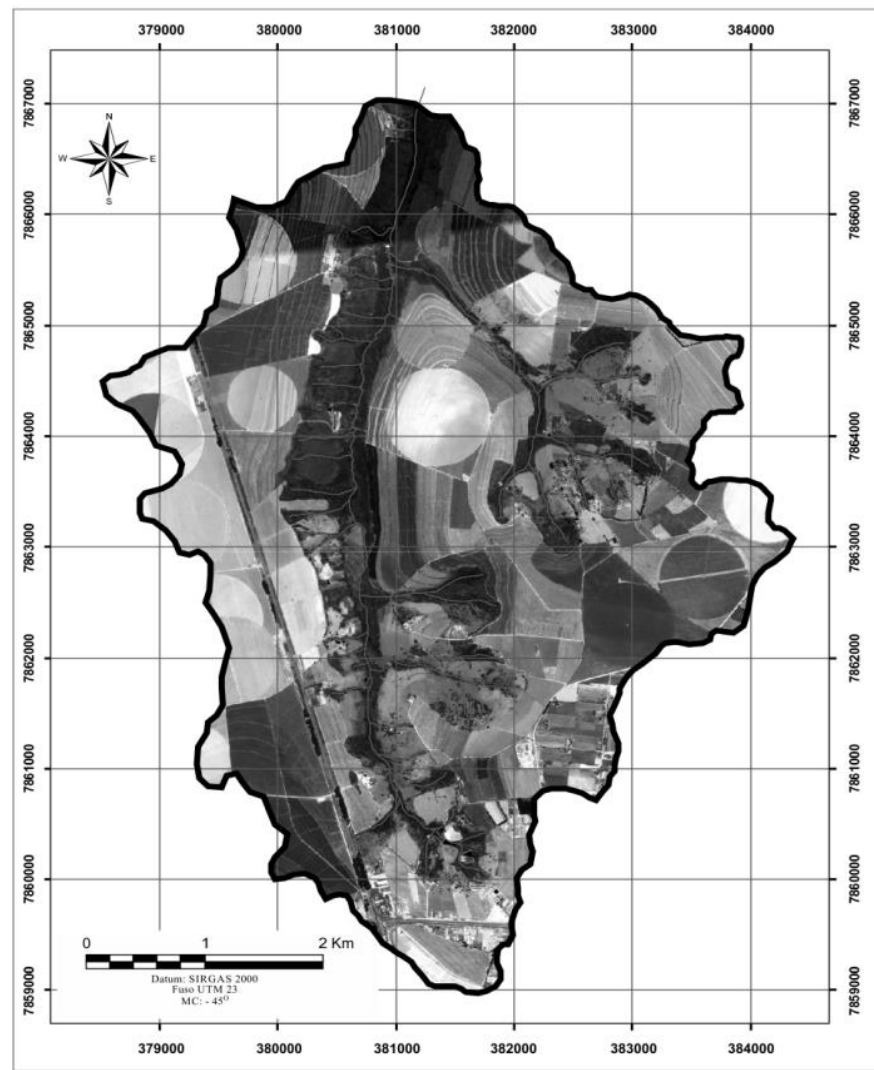

Figura 5. Imagem do Google Earth.

A Tabela 3 apresenta a área referente a cada uso do solo na sub-bacia estudada. Nesta observa-se que o uso do solo com maior incidência na subbacia estudada é de pastagem com $45,33 \%$ e o de menor é eucalipto com $0,74 \%$.

Tabela 3. Área de cada uso do solo na subbacia estudada (12/2011)

\begin{tabular}{ccc}
\hline Uso do solo & Área (ha) & $\%$ \\
\hline Café & 372,61 & 14,61 \\
Terra Preparada & 27,17 & 1,07 \\
Soja & 138,67 & 5,44 \\
Mata Nativa & 90,89 & 3,56 \\
Eucalipto & 18,88 & 0,74 \\
Cenoura & 126,89 & 4,97 \\
Milho & 305,80 & 11,99 \\
Milheto & 23,61 & 0,93 \\
Pastagem & $1.156,29$ & 45,33 \\
Construção & 48,20 & 1,89 \\
Rodovia & 54,95 & 2,15 \\
APP & 187,12 & 7,33 \\
\hline Total & $2.551,07$ & 100,00 \\
\hline
\end{tabular}

Após a visita de campo procedeu-se a classificação da imagem, conforme pode ser visualizado na Figura 6 . Os pontos de informação apresentados nesta figura representam os locais em que foi cadastrado, com auxilio do GPS, o uso da água informado pelo produtor.

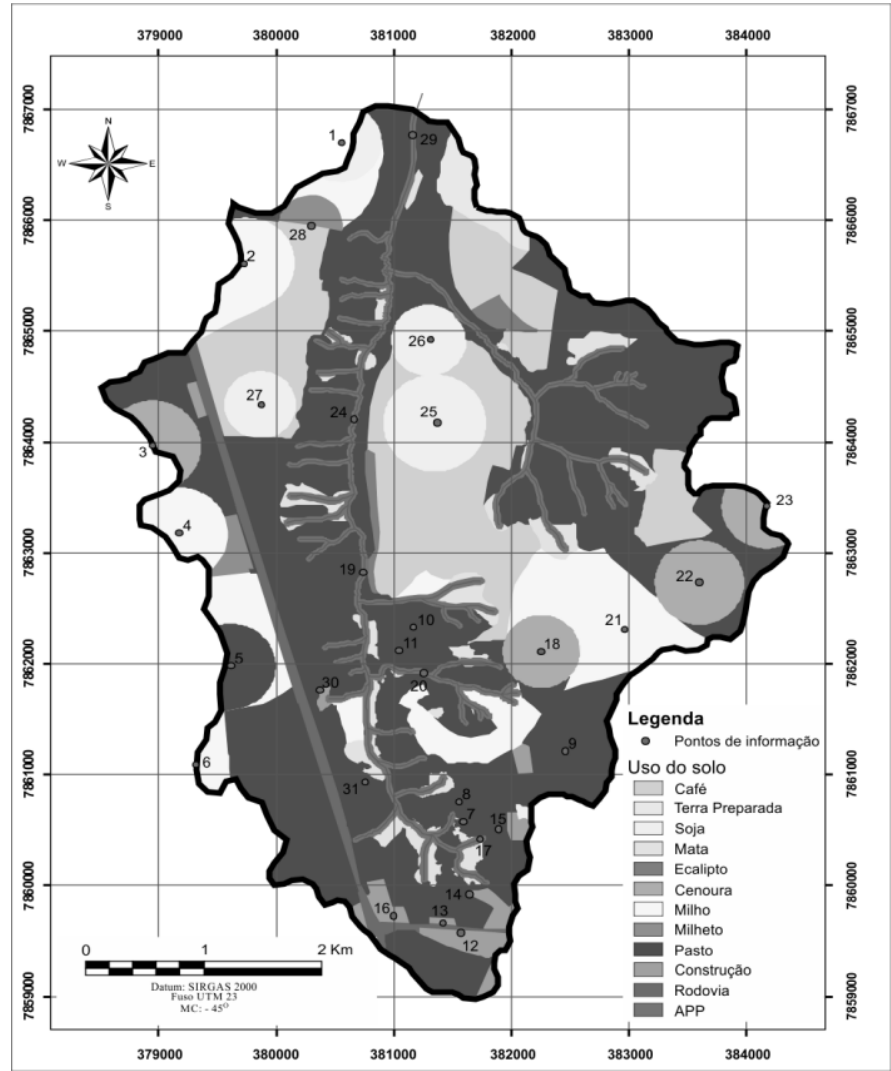

Figura 6. Imagem classificada.

A Tabela 4 apresenta as informações de consumo de água e tipo de captação de água em cada ponto de informação apresentado na Figura 6. Observa-se que foram encontrados 7 poços com um consumo total de, aproximadamente, $2.263 \mathrm{~L} \mathrm{~h}^{-1}$, enquanto que, foram encontradas 10 captações em rios e nascentes totalizando $357.570 \mathrm{~L} \mathrm{~h}^{-1}$. Os usos da água identificados foram a irrigação, dessedentação animal, abastecimento humano, lavadores de cenoura e de veículos e/ou máquinas agrícolas. 
Tabela 4. Uso, consumo e tipo de captação de água em cada ponto de informação

\begin{tabular}{|c|c|c|c|}
\hline $\begin{array}{l}\mathrm{N}^{\mathrm{o}} \text { do } \\
\text { ponto }\end{array}$ & $\begin{array}{c}\text { Uso da água informado } \\
\text { pelo produtor }\end{array}$ & $\begin{array}{c}\text { Consumo L } \\
\mathrm{h}^{-1}\end{array}$ & Captação \\
\hline $\begin{array}{l}1,2,3 \\
4,5,6\end{array}$ & Irrigação & - & Fora da bacia \\
\hline 7 & Dessedentação animal & 91,67 & Rio \\
\hline 8 & Dessedentação animal & 160,42 & Rio \\
\hline 9 & Dessedentação animal & 91,67 & Poço \\
\hline 10 & Dessedentação animal & 57,29 & Rio \\
\hline 11 & Dessedentação animal & 80,21 & Rio \\
\hline 12 & $\begin{array}{c}\text { Abastecimento humano } \\
60 \text { pessoas }\end{array}$ & 208,33 & Poço \\
\hline 13 & $\begin{array}{c}\text { Abastecimento humano } \\
130 \text { pessoas }\end{array}$ & 451,39 & Poço \\
\hline 14 & $\begin{array}{l}\text { Lavador de Cenoura } \\
\qquad 160 \mathrm{~h} / \mathrm{mês}\end{array}$ & 500,00 & 2 Poços \\
\hline 15 & Irrigação / Estufa & 625,00 & Poço \\
\hline 16 & $\begin{array}{c}\text { Abast. humano/ } \\
\text { Lavagem de veículos } \\
\text { ou máq. }\end{array}$ & 386,90 & Poço \\
\hline 17 & $\begin{array}{c}\text { Abastecimento humano } \\
45 \text { pessoas }\end{array}$ & 156,25 & Nascente \\
\hline 18 & Irrigação & $93.333,33$ & Rio - Ponto 19 \\
\hline 19 & Cap. de água do pivô 18 & - & - \\
\hline 20 & Cap. de água desativada & - & - \\
\hline 21 & $\begin{array}{c}\text { Pivô não está sendo } \\
\text { utilizado }\end{array}$ & - & Rio - Ponto 24 \\
\hline 22 & Irrigação & $131.250,00$ & Rio - Ponto 24 \\
\hline 23 & Irrigação & $131.250,00$ & Rio - Ponto 24 \\
\hline 24 & $\begin{array}{l}\text { Cap. de água dos } \\
\text { pivôs } 21,22 \text { e } 23\end{array}$ & - & - \\
\hline 25,26 & Pivô desativado & - & - \\
\hline 27 & $\begin{array}{l}\text { Pivô não está } \\
\text { sendo utilizado }\end{array}$ & - & Rio - Ponto 24 \\
\hline 28 & $\begin{array}{l}\text { Pivô não está } \\
\text { sendo utilizado }\end{array}$ & - & Rio - Ponto 29 \\
\hline 29 & $\begin{array}{l}\text { Cap. de água do } \\
\text { pivô } 28\end{array}$ & - & - \\
\hline 30 & Dessedentação animal & 160,42 & Nascente \\
\hline 31 & Dessedentação animal & 1031,25 & Nascente \\
\hline
\end{tabular}

\section{Área máxima possível para plantio de}

\section{cenoura e trigo irrigado}

Na determinação da área máxima possível para plantio de cenoura e trigo irrigados, no período de abril a julho, adotou-se como área útil de 1.778,43 ha, o qual corresponde aos usos terra preparada, soja, cenoura, milho, milheto e pastagem o qual permitem o plantio das referidas culturas.
Posteriormente, determinou-se a vazão máxima possível de ser outorgada por meio da equação da $\mathrm{Q}_{7,10}$ apresentada no Atlas Digital das Águas de Minas. Assim, para a área estudada que possui $25,51 \mathrm{~km}^{2}$ a vazão $\mathrm{Q}_{7,10}$ foi de $0,1146 \mathrm{~m}^{3} \mathrm{~s}^{-1}$, resultando em uma disponibilidade de água de $123.761 \mathrm{~L} \mathrm{~h}^{-1}$ que corresponde a $30 \%$ da $\mathrm{Q}_{7,10}$. Considerou-se que 21 horas é o número máximo possível de horas que se pode irrigar por dia, evitando-se com isso irrigar nas três horas do horário de pico em que a tarifa de energia elétrica é elevada. O ciclo da cenoura é em média de 120 dias, o que resultou em um volume máximo possível de ser outorgado durante os 120 dias de cultivo de, aproximadamente, 311.877 .886 litros de água.

Aplicando a equação 2 à série histórica dos dados meteorológicos, obteve-se os valores da $\mathrm{ET}_{\mathrm{p}}$ diária para os meses de abril a julho (Tabela 5). Nesta tabela apresenta-se ainda a precipitação média mensal obtida na estação meteorológica da Cooperativa Agropecuária do Alto Paranaíba (COPADAP). Os valores de ETp diária determinados para os meses de abril a junho, neste trabalho, estão de acordo com os valores apresentados por Silva et al. (2009) e Alves et al. (2010) para a mesma região de estudo. Os mapas disponibilizados no boletim agroclimatológico mensal pelo Instituto Nacional de Metereologia também apresentaram valores próximos aos determinados neste trabalho (INMET, 2014).

Tabela 5. ET $_{\mathrm{p}}$ diária e precipitação média mensal

\begin{tabular}{ccccc}
\hline Ano/mês & Abril & Maio & Junho & Julho \\
\hline ET $_{\text {p diária }(\mathrm{mm})}$ & 2,70 & 2,30 & 2,10 & 2,20 \\
$\begin{array}{c}\text { Precipitação média } \\
(\mathrm{mm})\end{array}$ & 87,10 & 44,20 & 14,10 & 14,90 \\
\hline
\end{tabular}


A obtenção da $\mathrm{ET}_{\mathrm{c}}$ total no período de irrigação das culturas cenoura e trigo foi obtida pela multiplicação do $\mathrm{K}_{\mathrm{c}}$ apresentado na Tabela 6 para as durações de cada fase fenológica da cultura. Fazendo o somatório da $\mathrm{ET}_{\mathrm{c}}$ de todo o ciclo da cenoura tem-se um valor de 256,98 $\mathrm{mm}$, enquanto que a precipitação total histórica neste mesmo período é de 160,30 mm, representando um déficit de 96,68 $\mathrm{mm}$ que deve ser suprido com irrigação. Marouelli et al. (2007) relatam que a necessidade de água da cultura da cenoura varia de 350 a $550 \mathrm{~mm}$ por ciclo. Segundo os autores este valor pode variar dependendo das condições climáticas, duração do ciclo da cultura e o sistema de irrigação.

Como é sabido cada milímetro de chuva ou irrigação fornece um litro de água por metro quadrado, portanto, $96,68 \mathrm{~mm}$ equivalem a 96,68 $\mathrm{L} \mathrm{m}^{-2}$ ou 966.800 $\mathrm{L} \mathrm{ha}^{-1}$. Portanto, com o volume máximo possível de ser outorgado para a bacia estudada, no período de abril a julho, é possível cultivar 322,69 ha de cenoura irrigada, o que representa aproximadamente $18 \%$ da área total possível de ser cultivada.

Para o trigo foram realizados os mesmos cálculos descritos para a cenoura, modificando apenas o número de dias de irrigação, pois para o trigo no ultimo estádio não se irriga. Assim, o cálculo foi realizado para um período de irrigação de 91 dias. Na Tabela 6 estão apresentados os valores da $\mathrm{ET}_{\mathrm{p}}$ diária, $\mathrm{ET}_{\mathrm{c}}, \mathrm{K}_{\mathrm{c}} \mathrm{e}$ precipitação para todos os estádios da cultura do trigo. Fazendo o somatório da $\mathrm{ET}_{\mathrm{c}}$ de todo o ciclo do trigo tem-se um valor de 212,67 mm, enquanto que a precipitação total histórica neste mesmo período é de $145,40 \mathrm{~mm}$, representando um déficit de 67,27 $\mathrm{mm}$ que deve ser suprido com irrigação.
Tabela 6. Cálculo da $\mathrm{ET}_{\mathrm{c}}(\mathrm{mm})$ para a cenoura durante todo o ciclo

\begin{tabular}{|c|c|c|c|c|c|c|c|}
\hline Meses & \multicolumn{2}{|c|}{ Abril } & \multicolumn{2}{|c|}{ Maio } & Junho & \multicolumn{2}{|c|}{ Julho } \\
\hline \multicolumn{8}{|c|}{ Cenoura } \\
\hline Estádio & 1 & 2 & 2 & 3 & 3 & 3 & 4 \\
\hline $\begin{array}{l}\text { Duração } \\
\text { em dias }\end{array}$ & 20 & 10 & 20 & 11 & 30 & 9 & 20 \\
\hline $\mathrm{ET}_{\mathrm{p}}$ diária & 2,70 & 2,70 & 2,30 & 2,30 & 2,10 & 2,10 & 2,20 \\
\hline $\mathrm{K}_{\mathrm{c}}$ & 0,70 & 0,88 & 0,88 & 1,05 & 1,05 & 1,05 & 0,95 \\
\hline $\mathrm{ET}_{\mathrm{c}}$ & 37,80 & 23,76 & 40,25 & 26,57 & 66,15 & 20,79 & 41,80 \\
\hline Precipitação & \multicolumn{2}{|c|}{87,10} & \multicolumn{2}{|c|}{44,20} & \multicolumn{2}{|c|}{14,10} & 14,90 \\
\hline \multicolumn{8}{|c|}{ Trigo } \\
\hline Estádio & 1 & 2 & 2 & 3 & 3 & 4 & - \\
\hline $\begin{array}{c}\text { Duração } \\
\text { em dias }\end{array}$ & 15 & 15 & 10 & 21 & 30 & 29 & - \\
\hline Etp diária & 2,70 & 2,70 & 2,30 & 2,30 & 2,10 & - & - \\
\hline $\mathrm{Kc}$ & 0,70 & 0,93 & 0,93 & 1,15 & 1,15 & - & - \\
\hline Etc & 28,35 & 37,46 & 21,28 & 55,55 & 70,04 & - & - \\
\hline Precipitação & \multicolumn{2}{|c|}{87,10} & \multicolumn{2}{|c|}{44,20} & 14,10 & - & - \\
\hline
\end{tabular}

Com o volume máximo possível de ser outorgado para a bacia estudada, no período de abril a julho, é possível cultivar 351,56 ha de trigo irrigado, o que representa aproximadamente $20 \%$ da área total possível de ser cultivada. Garrido et al. (1978) determinaram que a $\mathrm{ET}_{\mathrm{c}}$ total do ciclo do trigo foi de $378,4 \mathrm{~mm}$, para a região de Viçosa (MG), portanto o valor encontrado neste trabalho foi bem inferior ao determinado naquele. Este fato pode ser explicado pela grande diferença de altitude entre as duas regiões. Assunção (2002) destaca que a temperatura é determinante nos processos de evaporação do solo e transpiração das plantas, portanto as altitudes da região estudada (entre 840 e 1200 m) proporcionam a ocorrência de temperaturas amenas, mesmo durante o verão.

Portanto, observa-se que a cultura do Trigo apesar de necessitar de um período de 
irrigação 29 dias menor que a cultura da cenoura, apresentou um maior consumo hídrico devido aos maiores valores do coeficiente de cultura $(\mathrm{Kc})$ nas fases de desenvolvimento 2 e 3 , que são aquelas que constituem o maior período em que as culturas devem ser irrigadas.

Vale salientar que não foi encontrada nenhuma outorga nos arquivos disponibilizados pelo IGAM até o período deste estudo na área pesquisada.

\section{CONCLUSÕES}

A metodologia aplicada para mapear o uso atual do solo se mostrou eficiente, mas, onerosa para grandes áreas devido às imagens do Google Earth utilizadas não serem recentes o que vai demandar uma grande quantidade de horas em trabalhos de campo para ajustar o uso verificado na imagem com o uso atual. Com isso, verificou-se a necessidade da visita em campo de toda a área a ser estudada. No que se refere ao mapeamento do uso da água constatou-se a disponibilidade dos proprietários em auxiliar com as informações necessárias ao desenvolvimento deste estudo.

Ficou evidenciado neste trabalho que o fator limitante para a produção de cenoura e trigo na época de seca é a disponibilidade de água já que as áreas possíveis de serem cultivas são grandes, pois não observa-se na área nenhuma restrição quanto a fatores topográficos (que dificultam a mecanização) e edáficos (ocorrência de solos pedregosos, por exemplo). As únicas limitações quanto ao uso dessas duas culturas irrigadas devem-se as áreas de APP, Reserva Legal e outros usos impeditivos (construções e obras viárias).

\section{REFERÊNCIAS BIBLIOGRÁFICAS}

ALLEN, R.G.; PEREIRA, L.S.; RAES, D.; SMLTH, M. Guidelines for computing crop water requirements. Rome: FAO, 1998. 310 p. (Irrigation and Drainage Paper, 56).

ALVES, L. A.; ASSUNÇÃO, W. L. A oferta climática e a demanda hídrica das culturas irrigadas no município de São Gotardo (MG). In: IX Simpósio Brasileiro de Climatologia Geográfica, 9., Fortaleza. Anais... Ceará, 2010.

TONELLO, K. C. Análise hidroambiental da bacia hidrográfica da Cachoeira das Pombas, Guanhães, MG. 2005. 69 f. Dissertação (Mestrado em Ciência Florestal) - Universidade Federal de Viçosa, Minas Gerais.

ASSUNÇÃO. W.L. Climatologia da cafeicultura irrigada no município de Araguari (MG). 2002. 282 f. Tese (Doutorado em Geografia) - Faculdade de Ciências e Tecnologia, Universidade Estadual Paulista, Presidente Prudente, São Paulo.

CAMARGO, A.P. DE. Balanço Hídrico no Estado de São Paulo. Campinas: Instituto Agronômico de Campinas. 1971. 24p. (Boletim técnico 116).

DUARTE, S. M. A.; SILVA, I. F.; MEDEIROS, B. G. S.; ALENCAR, M. L. S. Levantamento de solo e declividade da microbacia hidrográfica Timbaúba no Brejo do Paraibano, através de técnicas de fotointerpretação e Sistema de Informações Geográficas. Revista de Biologia e Ciências da Terra, v.4, n.2, 2004.

ENVI - Environment for Visualizing Images. http://www.envi.com.br/index.php?link= Aster. 30 Nov. 2011. 
EUCLYDES, H. P. (org.). Atlas Digital das Águas de Minas. Viçosa. http://www.atlasdas aguas.ufv.br/. 05 Jan. 2012.

FERREIRA JUNIOR, R. M.; VIEIRA, E. M.; GOMES, I; MACHADO, L. M.; SIMÃO, M. L.; CARDOSO, E. L. Levantamento do uso e ocupação do entorno da represa de Nova Ponte - MG, utilizando os sistemas de informações geográficas (SIGs), para futura delimitação de parques aquícolas. In: XIII Simpósio Brasileiro de Geografia, 8., Viçosa. Anais... Viçosa: UFV, 2009.

GARRIDO, M.A.T.; SILVA, A.M.; SOUZA, M.A. Efeito de diferentes níveis de umidade do solo no rendimento do trigo na região Sul de Minas Gerais. Belo Horizonte: EPAMIG, 1978.

GLUFKE, C. Espécies recomendadas para recuperação de áreas degradadas. Porto Alegre: Fundação Zoobotânica do Rio Grande do Sul, 1999.

IGAM $a$ - Instituto Mineiro de Gestão das Águas. Outorga de direito de uso dos recursos hídricos.

http://www.igam.mg.gov.br/outorga. 05 Jan. 2012.

IGAM $b$ - Instituto Mineiro de Gestão das Águas. Legislação Estadual. http://www. siam.mg.gov.br/sla/action/Consulta.do. 05 Jan. 2012.

INMET - Instituto Nacional de Metereologia. Boletim Agroclimatológico Mensal. 15 Out. 2014.

LANNA, A.E. Economia dos Recursos Hídricos. 2000. Programa de Pós Graduação em Recursos Hídricos e Saneamento Ambiental - IPH/UFRGS.

MAROUELLI, W. A.; OLIVEIRA, R. A.; SILVA, W. L. C. Irrigação da Cultura da Cenoura. Brasília: Embrapa Hortaliça, 2007. 14p. Circular Técnica.

MERTEN, G. H. E; MINELlA, J. P. Qualidade da água em bacias hidrográficas rurais: um desafio atual para a sobrevivência futura. Revista Agroecologia e Desenvolvimento Rural Sustentável, v.3, n.4, p.33-38, 2002.

OLIVEIRA, L. H.; ILHA, M. S. O.; GONÇALVES, O. M.; YWASHIMA, L.; REIS, R. P. A. Levantamento do estado da arte: Água Tecnologias para construção habitacional mais sustentável. Projeto Finep. São Paulo, 2007.

RIBEIRO, A. G. O uso do método climatológico para a determinação prática de critérios de irrigação da lavoura cafeeira. In: SIMPÓSIO BRASILEIRO DE CLIMATOLOGIA GEOGRÁFICA, 4., Rio de Janeiro. Anais... Rio de Janeiro: UFRJ, 2000.

RIBEIRO, C. A. A. S.; CHAVES, M. A.; SOARES, V. P.; EUCLYDES, H. P. Modelos digitais de elevação hidrologicamente consistentes para a Amazônia Legal. In: II SIMPÓSIO DE RECURSOS HÍDRICOS DO CENTRO OESTE CAMPO GRANDE, 2., Campo Grande. Anais... Campo Grande, 2002.

ROCHA, C.H.B. Geoprocessamento: tecnologia transdisciplinar. Juiz de Fora, 2000. 220p.

SANTOS, H.G. Importância e evolução dos levantamentos de solos no Brasil. Boletim 
Informativo da Sociedade Brasileira de Ciência do Solo, Viçosa, v. 32, n. 1, p. 18-20, 2007.

SILVA, T. O; RIBEIRO, J. G.; ANDRADE, M. V. S. F.; SILVA, M. A. A.; ARAÚJO, F. C.; ALMEIDA, W. L.; DRUMOND, L. C. D.; RONCHI, C. P. Diferentes níveis de déficit hídrico na concentração da florada e seus efeitos no crescimento vegetativo de genótipos de coffea arabica na região do Alto Paranaíba-MG. In: VI SIMPÓSIO DE PESQUISA DOS CAFÉS DO BRASIL, Vitória. Anais... Vitória: EMBRAPA, 2009.

TESTONI, A. J. A. Importância da topografia na recuperação de áreas degradadas. Revista:
Unoesc \& Ciência - ACET, Joaçaba, v. 1, n. 1, p. 21-30, jan./jun. 2010.

TONELLO, K. C. Análise hidroambiental da bacia hidrográfica da Cachoeira das Pombas, Guanhães, MG. 2005. 69 f. Dissertação (Mestrado em Ciência Florestal) - Universidade Federal de Viçosa, Minas Gerais.

TORLAY, R. E OSHIRO, O. T. Obtenção de imagem do Google Earth para classificação de Uso e ocupação do solo. In: CONGRESSO DE INTERINSTITUCIONAL DE INICIAÇÃO CIENTÍFICA, 4., Campinas. Anais... Campinas: IAC, 2010. 